\title{
Article \\ Structures and Mechanical Properties of Some Dual-Phase Steels with Low Manganese Content
}

\author{
Constantin Dulucheanu*(D), Traian Lucian Severin*(D), Delia Aurora Cerlinca and Luminita Irimescu
}

check for updates

Citation: Dulucheanu, C.; Severin, T.L.; Cerlinca, D.A.; Irimescu, L. Structures and Mechanical Properties of Some Dual-Phase Steels with Low Manganese Content. Metals 2022, 12, 189. https://doi.org/10.3390/ met12020189

Academic Editor: Filippo Berto

Received: 29 December 2021

Accepted: 18 January 2022

Published: 20 January 2022

Publisher's Note: MDPI stays neutral with regard to jurisdictional claims in published maps and institutional affiliations.

Copyright: (c) 2022 by the authors. Licensee MDPI, Basel, Switzerland. This article is an open access article distributed under the terms and conditions of the Creative Commons Attribution (CC BY) license (https:// creativecommons.org/licenses/by/ $4.0 /)$.
Faculty of Mechanical Engineering, Automotive and Robotics, "Stefan cel Mare" University of Suceava, 13 University Street, 720229 Suceava, Romania; delia@usm.ro (D.A.C.); luminita.irimescu@usm.ro (L.I.) * Correspondence: dulu@usm.ro (C.D.); severin.traian@usm.ro (T.L.S.)

\begin{abstract}
In recent years, to reduce cars costs, research has been conducted on dual-phase steels with low manganese content (below 1.0\%). This study investigated the influence of technological parameters of heat treatment (heating temperature and cooling medium) on such steels' structures and mechanical properties. The ferrite-martensitic structures, specific for dual-phase steels, were obtained by intercritical quenching: heating of samples (made of alloys with $0.511 \% \mathrm{Mn}$, respectively $0.529 \% \mathrm{Mn}$ ) to temperatures located between critical points $\mathrm{Ac}_{1}$ and $\mathrm{Ac}_{3}$, followed by cooling in water without mechanical agitation and in water activated with ultrasounds at the frequency of $59 \mathrm{kHz}$. Through metallographic analyses and tensile tests, it was possible to determine the volume fraction of martensite, the ferrite microhardness, the ultimate tensile strength, the total elongation, and with the obtained data, their variations with the heating temperature and the cooling medium were established. Raising the heating temperature (between $760^{\circ} \mathrm{C}$ and $820^{\circ} \mathrm{C}$ ) and using ultrasounds at cooling increased the volume fraction of martensite and the ferrite microhardness. This fact has increased the mechanical strength and reduced the deformability of the studied dual-phase steels. Intercritical quenching in water activated with ultrasounds provided values of structural characteristics and mechanical properties very close to those obtained by quenching in water without mechanical agitation, but was accomplished using a higher-temperature heating. The results obtained were compared with those determined in previous research, performed on dual-phase steel with $1.90 \% \mathrm{Mn}$.
\end{abstract}

Keywords: dual-phase steel; low manganese content; intercritical quenching; ultrasounds; ferrite; martensite; mechanical properties

\section{Introduction}

The dual-phase steels are metallic materials increasingly used by the automotive industry to make some structural car body components that can be damaged during an accident. These steels' structure is formed by a soft and ductile ferrite matrix in which martensite (10 to 35\%) and a small amount of residual austenite (1 to $2 \%$ ) are homogeneously dispersed. They have, in general, a percentage of carbon less than $0.12 \%$, a content of manganese between $1.0 \%$ and $3.5 \%$, and elements such as $\mathrm{V}, \mathrm{Cr}, \mathrm{Mo}, \mathrm{Si}, \mathrm{Nb}, \mathrm{Ti}$ are to be found in chemical composition in proportions situated below 1\%; in the recent years, to reduce cars costs, research has been conducted on dual-phase steels in which the manganese content was less than $1 \%(0.5$ to $1 \% \mathrm{Mn})$ [1-14].

One of the technologies applied to produce these steels is intercritical quenching; the structure obtained, for the given chemical composition, is the result of combined action of the technological parameters of heat treatment (heating temperature, cooling rate etc.), their influence on the structure is directly reflected on mechanical properties as well. The heating temperature in the intercritical range $\left(\mathrm{A}_{\mathrm{c} 1}-\mathrm{A}_{\mathrm{c} 3}\right)$ and the stability of austenite during transformation through the martensitic mechanism influence the amount of austenite obtained by heating and, finally, the volume fraction of martensite in the structure of the 
dual-phase steel. The cooling rate from temperatures in the intercritical range determines the type of transformation products due to the cooling process. The transformation almost entirely of austenite to martensite is possible by using a high cooling rate; such a cooling rate allows obtaining a ferrite-martensite structure even in the case of steels with low carbon and alloying elements. On the other hand, increasing the cooling rate leads to higher internal stresses during the martensitic transformation and a higher density of dislocations in ferrite, which greatly influences the mechanical properties of these steels. A moderate cooling rate, whose value is limited only by the danger of achieving the pearlitic transformation, leads to obtaining a significant volume fraction of "new ferrite", with a low number of interstitial atoms $(C, N)$ in the crystal lattice (which increases the deformability of this constituent) [1-5,11-22].

During quenching, the contact between the workpiece and the cooling medium is particularly significant since large temperature differences cause the calefaction phenomenon (formation of a vapor film between the piece and the cooling medium), which changes the cooling capacity of the medium. Remarkable results were obtained by applying the ultrasonic oscillations to the medium where the quenching occurs. This destroys vapor films, thereby ensuring a more prolonged contact between the workpiece and the cooling medium. In this way, the cooling rate is increased, leading to a much stronger cooling, the quenching with ultrasounds being more efficient than the classical one [3,23-28].

The dual-phase steels have been studied at the "Stefan cel Mare" University of Suceava since 1992, and over the years research has been conducted on several categories of alloys [3,25,27]. In recent years, studies have been carried out on dual-phase steels with low manganese content [26,28-30]; in this article results obtained for two such alloys are presented.

\section{Materials and Methods}

The chemical compositions of the two studied alloys (denoted DP-A and DP-B) were determined with a FOUNDRY-MASTER Xpert Spectrophotometer (Oxford Instruments Analytical GmbH, Uedem, Germany). These are presented in Table 1. The initial structures of these alloys were composed of $85.30 \%$ ferrite and $14.70 \%$ pearlite for DP-A steel, respectively $83.90 \%$ ferrite and $16.10 \%$ pearlite for DP-B steel $[26,28,30]$.

Table 1. The chemical composition of the DP-A and DP-B steels.

\begin{tabular}{|c|c|c|c|c|c|c|c|}
\hline \multirow[t]{2}{*}{ Steel } & \multicolumn{7}{|c|}{ Chemical Elements (wt.\%) } \\
\hline & $\mathrm{C}$ & Mn & $\mathrm{Si}$ & $\mathrm{P}$ & $S$ & $\mathrm{Cr}$ & Mo \\
\hline \multirow{3}{*}{ DP-A } & 0.087 & 0.511 & 0.091 & 0.0036 & 0.0039 & 0.029 & 0.005 \\
\hline & $\mathrm{Ni}$ & $\mathrm{Al}$ & $\mathrm{Cu}$ & V & W & $\mathrm{Fe}$ & - \\
\hline & 0.049 & 0.003 & 0.082 & 0.003 & 0.003 & balance & - \\
\hline \multirow{4}{*}{ DP-B } & $\mathrm{C}$ & Mn & $\mathrm{Si}$ & $\mathrm{P}$ & $S$ & $\mathrm{Cr}$ & Mo \\
\hline & 0.101 & 0.529 & 0.091 & 0.0032 & 0.0037 & 0.036 & 0.005 \\
\hline & $\mathrm{Ni}$ & $\mathrm{Al}$ & $\mathrm{Cu}$ & $\mathrm{V}$ & W & $\mathrm{Pb}$ & $\mathrm{Fe}$ \\
\hline & 0.015 & 0.003 & 0.015 & 0.003 & 0.003 & 0.011 & balance \\
\hline
\end{tabular}

To obtain, by intercritical quenching, a ferrite-martensite structure that falls within the definition of dual-phase steels, it is necessary to know the critical points $\mathrm{Ac}_{1}$ and $\mathrm{Ac}_{3}$. The values of these critical points of the two steels studied were determined by dilatometric analyses performed with a DIL 402 Expedis-SUPREME Dilatometer (NETZSCH Gerätebau $\mathrm{GmbH}$, Uedem, Germany), they being: $\mathrm{Ac}_{1}=724.00{ }^{\circ} \mathrm{C}$ and $\mathrm{Ac}_{3}=899.40^{\circ} \mathrm{C}$ for DP-A steel, $\mathrm{Ac}_{1}=725.10^{\circ} \mathrm{C}$ and $\mathrm{Ac}_{3}=898.90^{\circ} \mathrm{C}$ for DP-B steel [31]. Then, samples from the two alloys (DP-A and DP-B) were subjected to intercritical quenching, heat treatments that had the following technological parameters [26,28,30]:

- $\quad$ the heating temperatures $\left(\mathrm{T}_{\mathrm{Q}}\right)$ were between 760 and $820{ }^{\circ} \mathrm{C}(760,780,800$, and $82{ }^{\circ} \mathrm{C}$ ), values established according to the position of the critical points $\mathrm{Ac}_{1}$ and $\mathrm{Ac}_{3}$; 
- the heating was conducted at constant values of the $\mathrm{T}_{\mathrm{Q}}$ temperature for $30 \mathrm{~min}$ (in an electric laboratory furnace Nabertherm LT 40/11/P330, Nabertherm GmbH, Uedem, Germany);

- the cooling was conducted in an LBS 2 bath (Falc Instruments S.R.L., Treviglio, Italy), in two ways: in water with the temperature of $20^{\circ} \mathrm{C}$, without mechanical agitation (denoted $\mathrm{W}$ ) and in water with the temperature of $20^{\circ} \mathrm{C}$, activated with ultrasounds, at the frequency of $59 \mathrm{kHz}$ (denoted US59).

Next, on the quenched samples, by metallographic analyses, the volume fraction of martensite and the ferrite microhardness were determined. The surfaces needed metallographic analyses (seven samples for each version of intercritical quenching) were obtained by processing with Hot Mounting Press OPAL 410 and Grinding/Polishing Machine SAPHIR 530 (ATM GmbH, Uedem, Germany). The ferrite-martensite structures were highlighted by the following metallographic etchant: picric acid $4 \%$ solution in alcohol (etching time-60 s) and then nital 2\% (etching time-5 s). After the metallographic etchant, the martensite appeared as "dark" regions on micrographics, and the ferrite beads as the "white" regions. The analyses were performed with a LEXT OLS4100 Laser Microscope, (Olympus Corporation, Tokyo Japan) and OLYMPUS Stream MOTION Image Analysis Software, as well as a MicroHardness Tester DuraScan 70 (Emco Prüfmaschinen-Test $\mathrm{GmbH}, \mathrm{Kuchl}$, Austria), the test load of the Vickers indenter being $0.098 \mathrm{~N}$ (0.01 kgf); the ferrite microhardness was determined in compliance with EN ISO 6507-1:2018, "Metallic materials-Vickers hardness test-Part 1: Test method". Five micrographs and five microhardness measurements were performed on each metallographic sample [26,28,30,32].

The mechanical properties obtained by the heat treatments presented above (ultimate tensile strength and total elongation) were determined by tensile tests performed on a QUASAR 600 universal testing machine (Cesare GALDABINI SpA, Treviglio, Italy), following the provisions of EN ISO 6892-1:2019, "Metallic material-Tensile testing-Part 1: Method of test at room temperature"; cylindrical specimens with a diameter of $5 \mathrm{~mm}$ and initial length between markers (in the calibrated portion) $25 \mathrm{~mm}$ were used; batches consisting of ten specimens for each heating temperature and quench medium. Tensile tests were also conducted on ten specimens with the initial ferrite-pearlite structure $[28,30]$.

The results obtained for the two dual-phase steels with low manganese content (DPA and DP-B) were compared with those determined from previous research $[3,23,25]$, performed on a steel with 1.90\% Mn $(0.09 \%$ C, $1.90 \% \mathrm{Mn}, 0.06 \% \mathrm{Si}, 0.10 \% \mathrm{Cr}, 0.09 \% \mathrm{Ni}$, $0.03 \% \mathrm{Mo}, 0.012 \% \mathrm{Al}, 0.15 \% \mathrm{Cu}, 0.019 \% \mathrm{P}, 0.011 \% \mathrm{~S})$, alloy noted $\mathrm{DPS}_{1.90 \mathrm{Mn}}$ in this article. Compared to the DP-A and DP-B alloys, the higher manganese content determined a lower position of the critical points $A_{c 1}$ and $A_{c 3}\left(A_{c 1}=703{ }^{\circ} \mathrm{C}, A_{c 3}=839{ }^{\circ} \mathrm{C}\right)$. For this reason, the intercritical quenching of $\mathrm{DPS}_{1.9 \mathrm{Mn}}$ steel (in water with a temperature of $20^{\circ} \mathrm{C}$ ) was performed from temperatures between 740 and $820^{\circ} \mathrm{C}$.

\section{Results and Discussions}

\subsection{Influence of Intercritical Quenching on the Structure of DP-A and DP-B Steels}

Since the values of the mechanical characteristics of dual-phase steel depend on the structure $[1-5,10-12,19,21]$, first, the influence of the technological parameters of the intercritical quenching (heating temperature and cooling medium) on the volume fraction of martensite $\left(\mathrm{V}_{\mathrm{M}}\right)$ and the ferrite microhardness (HV0.01) was analyzed; the results obtained for the two dual-phase studied are presented in Tables 2 and 3, Figures 1 and 2, [26,28,30].

Table 2. Volume fraction of martensite and ferrite microhardness for DP-A steel (average values).

\begin{tabular}{|c|c|c|c|c|c|c|c|c|}
\hline \multirow{2}{*}{$\frac{\mathrm{T}_{\mathrm{Q}}\left({ }^{\circ} \mathrm{C}\right)}{\text { Cooling Medium }}$} & \multicolumn{2}{|c|}{760} & \multicolumn{2}{|c|}{780} & \multicolumn{2}{|c|}{800} & \multicolumn{2}{|c|}{820} \\
\hline & $\mathbf{W}$ & US59 & $\mathbf{W}$ & US59 & $\mathbf{W}$ & US59 & $\mathbf{W}$ & US59 \\
\hline $\mathrm{V}_{\mathbf{M}}(\%)$ & 20.19 & 23.74 & 23.83 & 28.15 & 29.41 & 32.96 & 36.98 & 40.71 \\
\hline HV0.01 & 170.43 & 181.51 & 182.37 & 188.11 & 188.54 & 191.94 & 192.11 & 193.46 \\
\hline
\end{tabular}


Table 3. Volume fraction of martensite and ferrite microhardness for DP-B steel (average values).

\begin{tabular}{ccccccccc}
\hline $\mathrm{T}_{\mathbf{Q}}\left({ }^{\circ} \mathbf{C}\right)$ & \multicolumn{2}{c}{$\mathbf{7 6 0}$} & \multicolumn{2}{c}{$\mathbf{7 8 0}$} & \multicolumn{2}{c}{$\mathbf{8 0 0}$} & $\mathbf{8 2 0}$ \\
\hline Cooling medium & $\mathbf{W}$ & US59 & $\mathbf{W}$ & US59 & W & US59 & W & US59 \\
$\mathbf{V}_{\mathbf{M}} \mathbf{( \% )}$ & 22.10 & 25.24 & 25.51 & 28.98 & 30.40 & 33.82 & 38.13 & 42.21 \\
HV0.01 & 184.77 & 194.12 & 194.63 & 198.55 & 199.28 & 202.25 & 202.53 & 203.67 \\
\hline
\end{tabular}

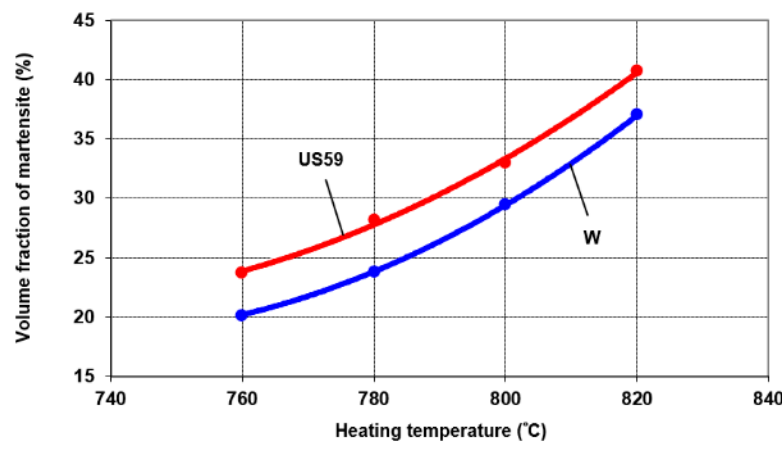

(a)

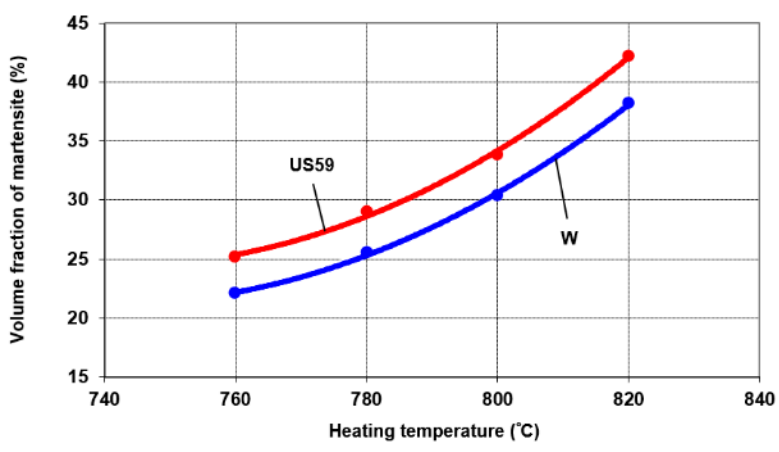

(b)

Figure 1. Variation of volume fraction of martensite with heating temperature and cooling medium:

(a) DP-A steel; (b) DP-B steel.

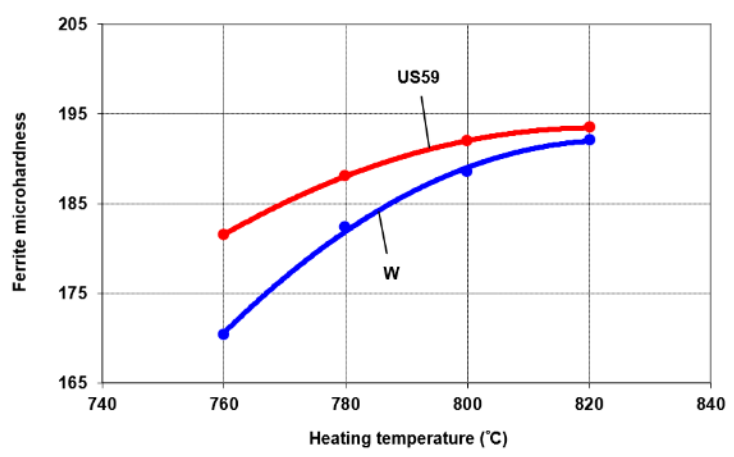

(a)

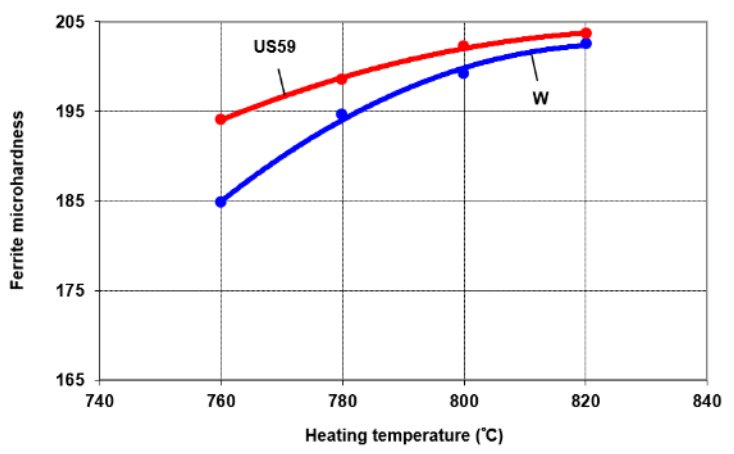

(b)

Figure 2. Variation of ferrite microhardness with heating temperature and cooling medium: (a) DP-A steel; (b) DP-B steel.

Raising the $T_{Q}$ temperature in the intercritical range $\left(\mathrm{Ac}_{1}-\mathrm{Ac}_{3}\right)$ has caused an increase in the amount of austenite obtained by heating, a phase which, by quenching in water without mechanical agitation (W) and in water activated with ultrasounds (US59), has turned into martensite. Thus, the rise in heating temperature $\left(\mathrm{T}_{\mathrm{Q}}\right)$ has led to an increase in the volume fraction of martensite $\left(V_{M}\right)$ in structures of the DP-A and DP-B steels (Tables 2 and 3, Figure 1).

Also, for same heating temperatures, the use of ultrasounds in cooling has led to increasing the volume fraction of martensite $\left(V_{M}\right)$, Tables 2 and 3, Figure 1; for example, in the DP-A steel samples, for $\mathrm{T}_{\mathrm{Q}}=760^{\circ} \mathrm{C}, \mathrm{V}_{\mathrm{M}}$ increased with 3.55 percent (from $20.19 \%$ to $23.74 \%$ ), and in the samples of DP-B steel, for $\mathrm{T}_{\mathrm{Q}}=820^{\circ} \mathrm{C}, \mathrm{V}_{\mathrm{M}}$ increased with 4.08 percent (from $38.13 \%$ to $42.21 \%$ ). The ultrasonic quenching medium eliminates one of the most dangerous phases of the cooling (calefaction), enhances heat exchange between product and cooling medium, and reduce the quenching deformations; on the other hand, the additional energy intake increases the volume fraction of martensite formed at quenching and reduces the amount of residual austenite [3,23-28].

The mechanical properties of dual-phase steel (in particular those of strength) are also influenced by the carbon content of martensite $\left(C_{M}\right)$, not only by the amount of this 
phase $\left(V_{M}\right)[2,5,10-12,26,31,32]$. The carbon content of martensite $\left(C_{M}\right)$ can be determined by $\mathrm{X}$-ray diffraction analysis, or it can be calculated with different equations, one of them being proposed by G.R. Speich and R.L. Miller [2,28,33]:

$$
C_{M}=C_{o}+\frac{\rho_{F}}{\rho_{M}} \cdot\left(\frac{100}{V_{M}}-1\right) \cdot\left(C_{o}-C_{F}\right)
$$

In which: $\mathrm{C}_{\mathrm{M}}$ is the carbon content of the martensite; $\mathrm{C}_{\mathrm{O}}$-the carbon content of the steel; $C_{F}$-the carbon content of the ferrite, $\left(C_{F}=0.002 \%\right) ; V_{M}$-the volume fraction of martensite; $\rho_{\mathrm{F}}$-the density of the ferrite; $\rho_{\mathrm{M}}$-the density of the martensite, $\left(\rho_{\mathrm{F}} / \rho_{\mathrm{M}}=1.025\right)[2,28,34]$; using this equation, values of the carbon content of martensite $\left(\mathrm{C}_{\mathrm{M}}\right)$ ranged from $0.431 \%$ for $\mathrm{V}_{\mathrm{M}}=20.19 \%\left(\mathrm{~T}_{\mathrm{Q}}=760{ }^{\circ} \mathrm{C} / \mathrm{W}\right)$ and $0.213 \%$ for $\mathrm{V}_{\mathrm{M}}=40.71 \%$ $\left(\mathrm{T}_{\mathrm{Q}}=820{ }^{\circ} \mathrm{C} / \mathrm{US} 59\right)$, to the DP-A steel and from $0.458 \%$ for $\mathrm{V}_{\mathrm{M}}=22.10 \%\left(\mathrm{~T}_{\mathrm{Q}}=760{ }^{\circ} \mathrm{C} / \mathrm{W}\right)$ and $0.239 \%$ for $\mathrm{V}_{\mathrm{M}}=42.21 \%\left(\mathrm{~T}_{\mathrm{Q}}=820^{\circ} \mathrm{C} / \mathrm{US5} 9\right)$, to the DP-B steel [28].

The martensite obtained by quenching from $760{ }^{\circ} \mathrm{C}$ in water without mechanical agitation (W) was in the form of small islands, situated mainly at the boundaries of the ferrite grains (Figure 3), most of them being located in regions which, in initial structure, was pearlite; this, by heating over the critical point $A c_{1}$, was transformed into austenite, from which, through quenching, martensite resulted. This transformation mechanism led to a volume fraction of martensite $\left(V_{M}\right)$ of approx. $14.70 \%$ in the case of DP-A steel, respectively $16.10 \%$ in the case of DP-B steel, percentages that constitute the equivalent of the amount of pearlite from the initial structures. The difference of martensite from $5.49 \%$ up to $20.19 \%$ for DP-A steel, respectively $6.0 \%$ up to $22.10 \%$ for DP-B steel (Tables 2 and 3), resulted from austenite obtained by the allotropic transformation of the ferrite; the ultrasonic quenching medium increased the cooling rate, which led to an increase in the volume fraction of martensite $\left(\mathrm{V}_{\mathrm{M}}\right)$ obtained in this way. Raising the heating temperature $\left(\mathrm{T}_{\mathrm{Q}}\right)$ between 760 and $820^{\circ} \mathrm{C}$ caused an increase in the amount of austenite that was formed by the allotropic transformation of the ferrite, which led to the rise in the volume fraction of martensite that resulted from quenching, both in water without mechanical agitation (W), and in water activated with ultrasounds (US59). At the same time, with the rising of the volume fraction of martensite in structures (and decreasing the amount of ferrite), an increase in the size of the martensite islands is observed (Figures 3 and 4). Furthermore, a tendency of their connection and the formation of a network around the ferrite grains are marked $[26,28]$.

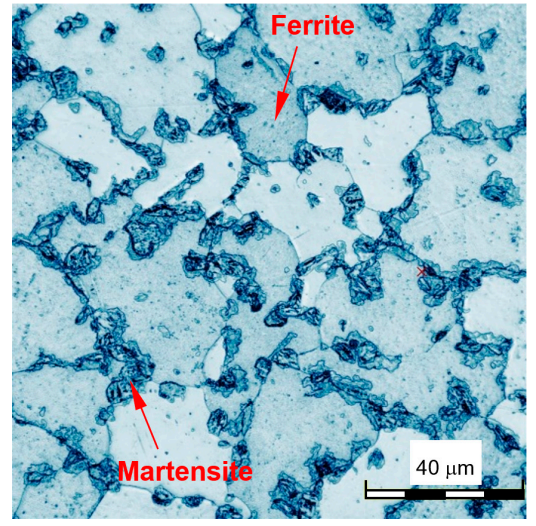

(a)

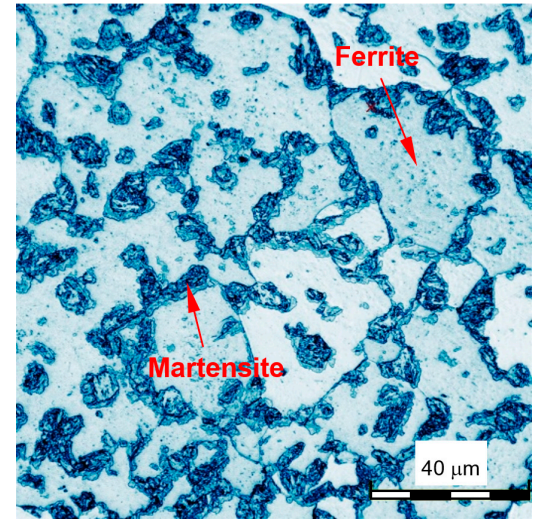

(b)

Figure 3. Microstructures of the DP-A steel (laser micrographs): (a): $\mathrm{T}_{\mathrm{Q}}=760{ }^{\circ} \mathrm{C} / \mathrm{W} ;(\mathbf{b}) \mathrm{T}_{\mathrm{Q}}=800{ }^{\circ} \mathrm{C} / \mathrm{US} 59$. 


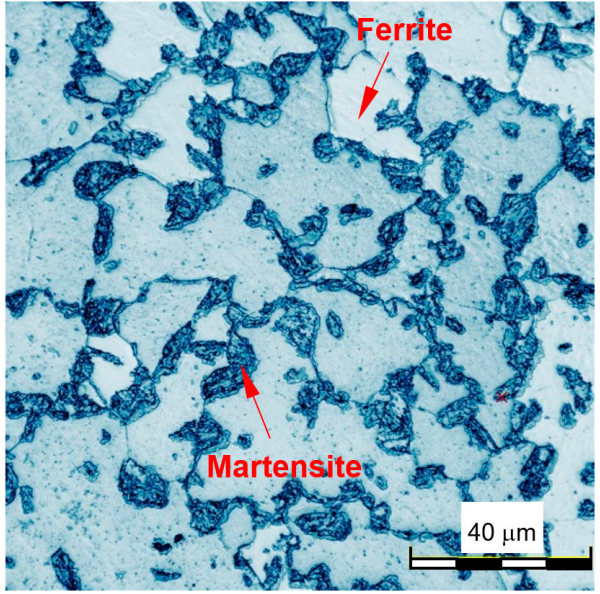

(a)

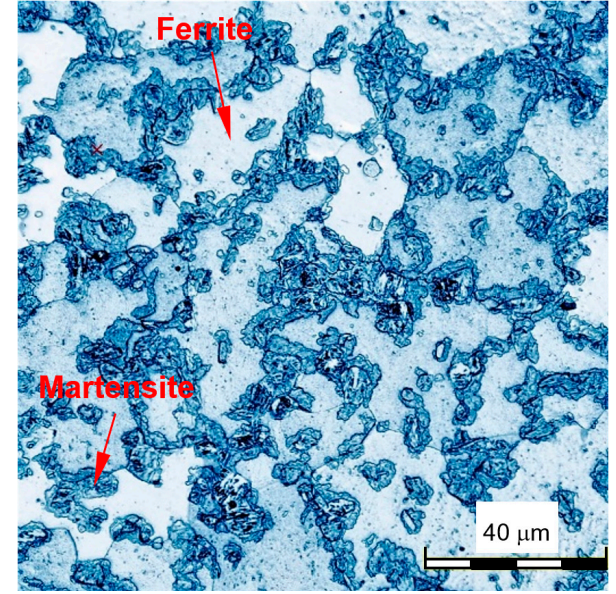

(b)

Figure 4. Microstructures of the DP-B steel (laser micrographs): $(\mathbf{a}): \mathrm{T}_{\mathrm{Q}}=780{ }^{\circ} \mathrm{C} / \mathrm{W} ;(\mathbf{b}) \mathrm{T}_{\mathrm{Q}}=820{ }^{\circ} \mathrm{C} / \mathrm{US} 59$.

The technological parameters of the intercritical quenching also influenced the ferrite microhardness (HV0.01); this has increased with both the raising of the heating temperature $\left(\mathrm{T}_{\mathrm{Q}}\right)$ and the use of ultrasounds at cooling (Tables 2 and 3, Figure 2). In the initial structures (ferrite-pearlite structure), the values of ferrite microhardness were 164.18 HV0.01 for DP-A steel, respectively 167.82 HV0.01 for DP-B steel. The increase in the number of interstitial atoms $(C, N)$ and density of dislocations in the crystal lattice of ferrite caused, most probably, the increase in the microhardness of this phase $[2,26,28,35]$.

\subsection{Influence of Intercritical Quenching on the Mechanical Properties of DP-A and DP-B Steels}

The tensile tests applied to the intercritical quenched specimens led to the results in Tables 4 and 5, Figures 5-10; for the specimens with the initial structure (ferrite-pearlite structure), the tensile tests determined to the following average values of the ultimate tensile strength $\left(R_{m}\right)$ and total elongation $\left(A_{5}\right): R_{m}=556.12 \mathrm{MPa}$ and $A_{5}=26.14 \%$ for DP-A steel, respectively $R_{m}=560.65 \mathrm{MPa}$ and $A_{5}=25.93 \%$ for DP-B steel $[28,30]$. The ferritemartensite structures obtained by intercritical quenching ensured (for both studied alloys) higher ultimate tensile strengths and smaller total elongations than those determined in the specimens with ferrite-pearlite structures.

Table 4. Ultimate tensile strength and total elongation for DP-A steel (average values).

\begin{tabular}{ccccccccc}
\hline $\mathbf{T}_{\mathbf{Q}}\left({ }^{\circ} \mathbf{C}\right)$ & \multicolumn{2}{c}{$\mathbf{7 6 0}$} & \multicolumn{2}{c}{$\mathbf{7 8 0}$} & \multicolumn{2}{c}{$\mathbf{8 0 0}$} & & $\mathbf{8 2 0}$ \\
\hline Cooling medium & $\mathbf{W}$ & US59 & $\mathbf{W}$ & US59 & W & US59 & W & US59 \\
$\mathbf{R}_{\mathbf{m}}(\mathbf{M P a})$ & 631.32 & 658.86 & 661.49 & 682.24 & 684.38 & 700.78 & 701.97 & 708.34 \\
$\mathbf{A}_{\mathbf{5}} \mathbf{( \% )}$ & 24.46 & 22.67 & 22.01 & 20.73 & 20.08 & 19.23 & 19.04 & 18.67 \\
\hline
\end{tabular}

Table 5. Ultimate tensile strength and total elongation for DP-B steel (average values).

\begin{tabular}{ccccccccc}
\hline $\mathrm{T}_{\mathbf{Q}}\left({ }^{\circ} \mathbf{C}\right)$ & \multicolumn{2}{c}{$\mathbf{7 6 0}$} & \multicolumn{2}{c}{$\mathbf{7 8 0}$} & \multicolumn{2}{c}{$\mathbf{8 0 0}$} & \multicolumn{3}{c}{$\mathbf{8 2 0}$} \\
\hline Cooling medium & $\mathbf{W}$ & US59 & W & US59 & W & US59 & W & US59 \\
$\mathbf{R}_{\mathbf{m}}(\mathbf{M P a})$ & 637.92 & 669.43 & 672.75 & 695.51 & 698.62 & 714.92 & 718.37 & 727.66 \\
$\mathbf{A}_{\mathbf{5}}(\mathbf{\%})$ & 23.29 & 21.38 & 20.95 & 19.84 & 19.29 & 18.68 & 18.59 & 18.23 \\
\hline
\end{tabular}




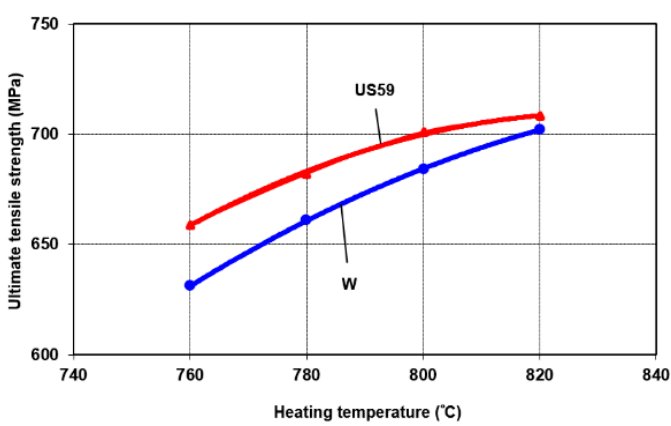

(a)

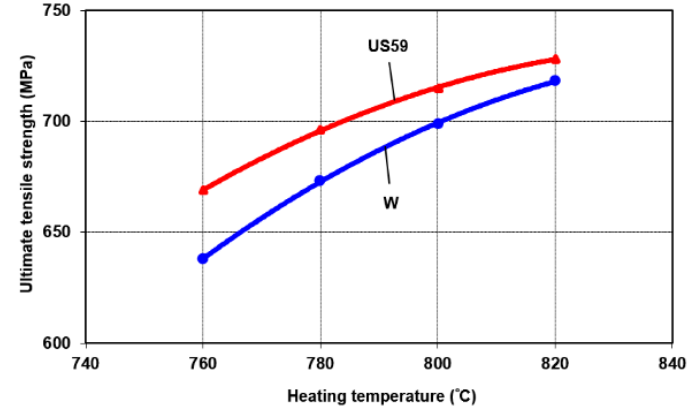

(b)

Figure 5. Variation of ultimate tensile strength with heating temperature and cooling medium: (a) DP-A steel; (b) DP-B steel.

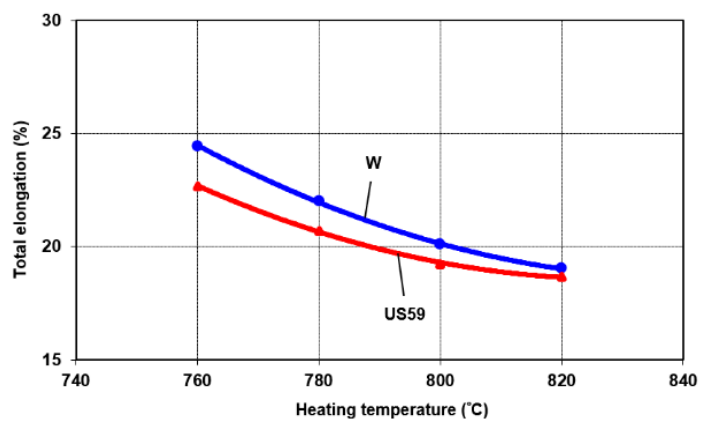

(a)

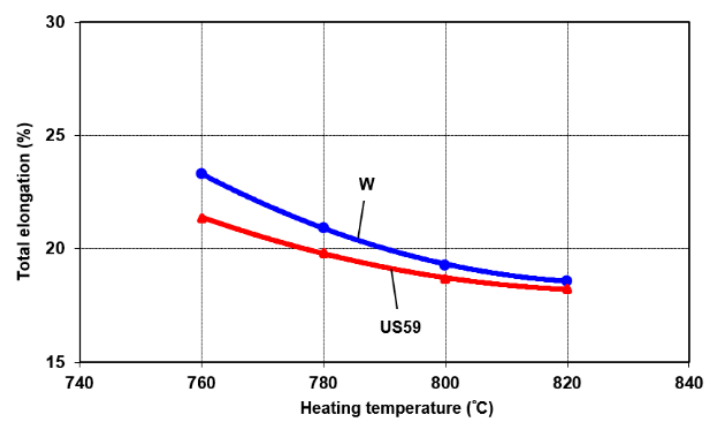

(b)

Figure 6. Variation of total elongation with heating temperature and cooling medium: (a) DP-A steel; (b) DP-B steel.

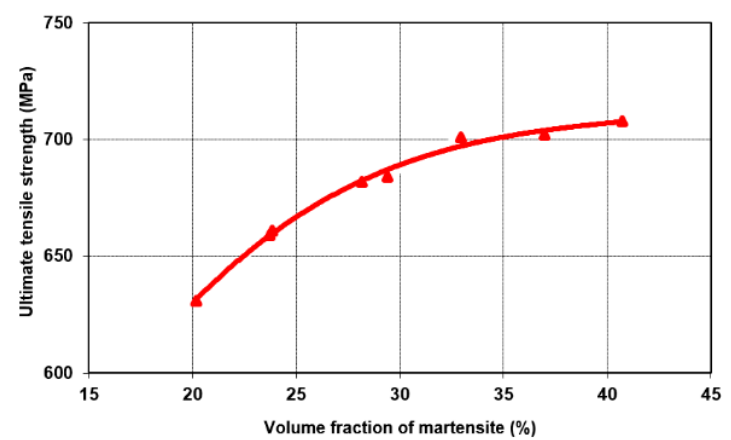

(a)

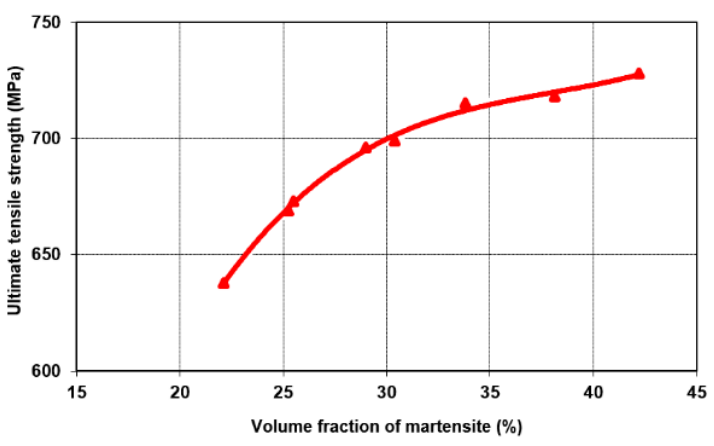

(b)

Figure 7. Variation of ultimate tensile strength with volume fraction of martensite: (a) DP-A steel; (b) DP-B steel.

The increase in the volume fraction of martensite $\left(V_{M}\right)$ and ferrite microhardness (HV0.01) due to the rise in quenching temperature $\left(\mathrm{T}_{\mathrm{Q}}\right)$ has led to an increase of the ultimate tensile strength $\left(R_{m}\right)$ and the decrease of the total elongation $\left(A_{5}\right)$ of the two dual-phase steels studied (Tables 4 and 5, Figures 5 and 6). 


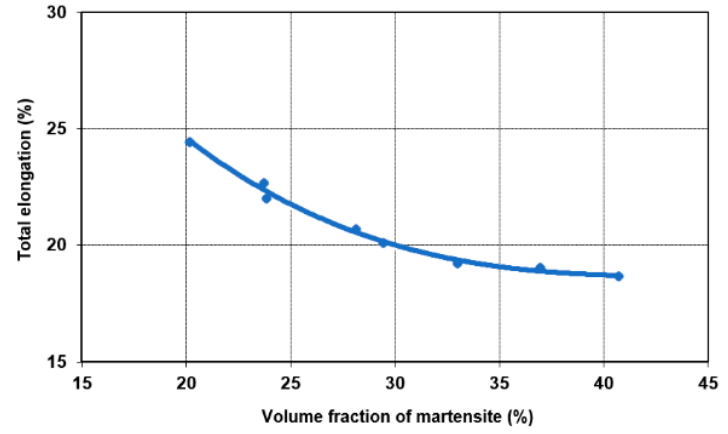

(a)

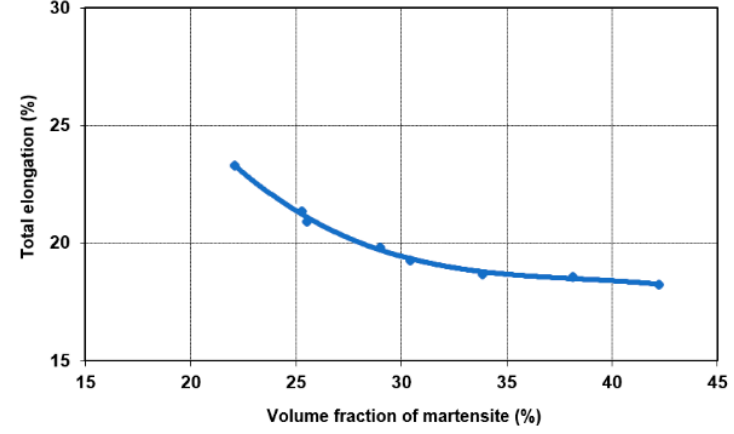

(b)

Figure 8. Variation of total elongation with volume fraction of martensite: (a) DP-A steel; (b) DP-B steel.

Also, for same heating temperatures, cooling in water activated with ultrasounds (US59) has determined to increase the strength characteristics $\left(R_{m}\right)$ and decrease deformability $\left(A_{5}\right)$, compared to the values obtained at quenching in water without mechanical agitation $(\mathrm{W})$; this effect was also generated by the increase in the volume fraction of martensite $\left(\mathrm{V}_{\mathrm{M}}\right)$ and ferrite microhardness (HV0.01), Tables 4 and 5, Figures 5 and 6. For example, to the specimens made of DP-A steel, for $\mathrm{T}_{\mathrm{Q}}=760^{\circ} \mathrm{C}$, the ultimate tensile strength $\left(\mathrm{R}_{\mathrm{m}}\right)$ increased with $27.54 \mathrm{MPa}$, from $631.32 \mathrm{MPa}$ to $658.86 \mathrm{MPa}$, and the total elongation $\left(\mathrm{A}_{5}\right)$ decreased with 1.79 percent, from $24.46 \%$ to $22.67 \%$; to the specimens made of DP-B steel, for $\mathrm{T}_{\mathrm{Q}}=800{ }^{\circ} \mathrm{C}$, the ultimate tensile strength $\left(\mathrm{R}_{\mathrm{m}}\right)$ increased with $16.30 \mathrm{MPa}$, from 698.62 MPa to 714.92 $\mathrm{MPa}$, and the total elongation $\left(\mathrm{A}_{5}\right)$ decreased with 0.61 percent, from $19.29 \%$ to $18.68 \%$ [28].

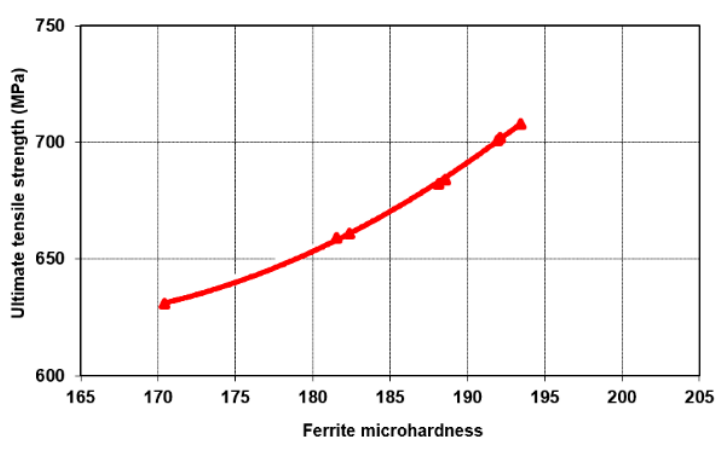

(a)

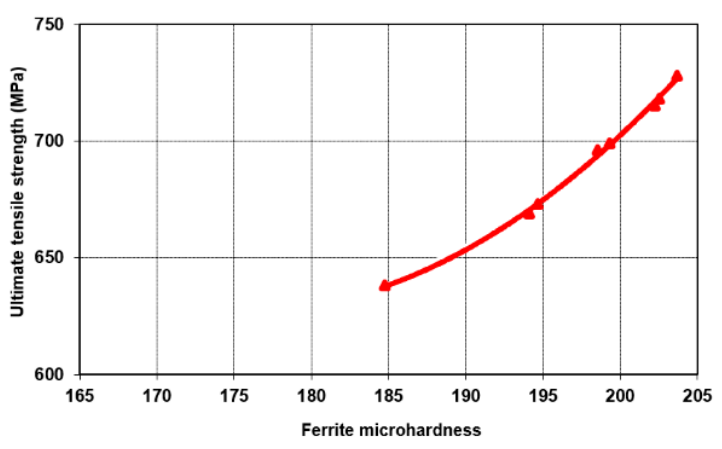

(b)

Figure 9. Variation of ultimate tensile strength with ferrite microhardness: (a) DP-A steel; (b) DP-B steel.

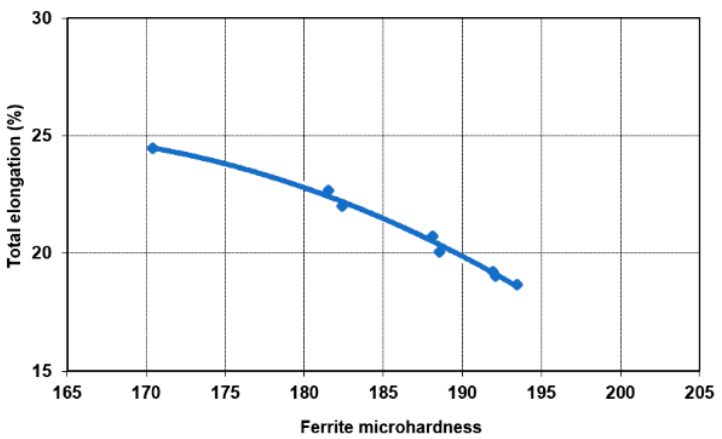

(a)

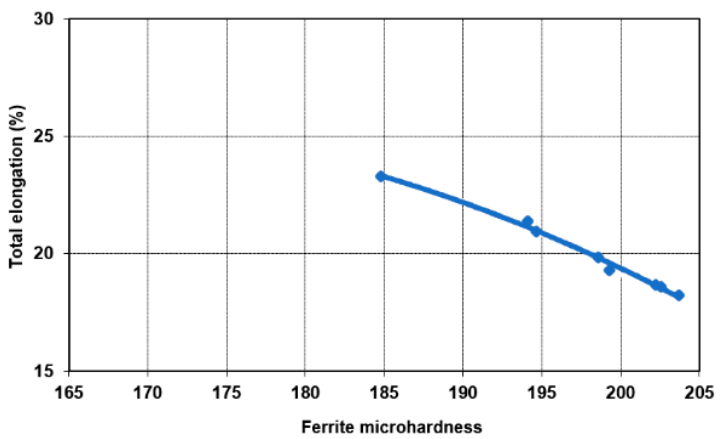

(b)

Figure 10. Variation of total elongation with ferrite microhardness: (a) DP-A steel; (b) DP-B steel. 
In dual-phase steels, the variation of the volume fraction of martensite $\left(V_{M}\right)$ has two contradictory effects on the mechanical characteristics: on the one hand, for example, the strength properties increase with increasing the volume fraction of martensite $\left(V_{M}\right)$, and on the other hand, the carbon content of martensite $\left(\mathrm{C}_{\mathrm{M}}\right)$ decreases; and hence, its strength decreases with an increase in the volume fraction of martensite $\left(V_{M}\right)$ $[5,10-12,28,33,34]$. The variation of the mechanical characteristics of the two steels $\left(R_{m}\right.$, $\left.A_{5}\right)$ depending on the volume fraction of martensite in the structure $\left(V_{M}\right)$ is not linear (Figures 7 and 8), being influenced by the carbon content of martensite $\left(\mathrm{C}_{\mathrm{M}}\right)$. For $\mathrm{V}_{\mathrm{M}}$ between $20.19 \%\left(C_{M}=0.431 \%\right)$ and approx. $28 \%\left(C_{M}=0.311 \%\right)$, to the DP-A steel and for $V_{M}$ between $22.10 \%\left(C_{M}=0.458 \%\right)$ and approx. $30 \%\left(C_{M}=0.337 \%\right)$, to the DP-B steel, the variation of $R_{m}$ and $A_{5}$ is more intense, than for $V_{M}$ between $28 \%\left(C_{M}=0.311 \%\right)$ and $40.71 \%$ $\left(C_{M}=0.213 \%\right)$, respectively between $30 \%\left(C_{M}=0.337 \%\right)$ and $42.21 \%\left(C_{M}=0.239 \%\right)$ [28].

Unlike the nonlinear variation of the mechanical characteristics according to the volume fraction of martensite $\left(V_{M}\right)$, their evolution $\left(R_{m}, A_{5}\right)$ according to the ferrite microhardness (HV0.01) is almost linear (Figures 9 and 10) [28].

The data in Tables $2-5$ show (for both steels studied) that the additional energy intake assured by the ultrasounds with the frequency of $59 \mathrm{kHz}$ determined obtaining of values for the volume fraction of martensite $\left(\mathrm{V}_{\mathrm{M}}\right)$, ferrite microhardness (HV0.01), ultimate tensile strength $\left(\mathrm{R}_{\mathrm{m}}\right)$, and total elongation $\left(\mathrm{A}_{5}\right)$ is very close to those obtained by quenching in water $(\mathrm{W})$, but with heating at a higher $\mathrm{T}_{\mathrm{Q}}$ temperature. For example, the results achieved by quenching $\mathrm{T}_{\mathrm{Q}}=760^{\circ} \mathrm{C} / \mathrm{US5} 5$ are very close to those obtained by quenching $\mathrm{T}_{\mathrm{Q}}=780{ }^{\circ} \mathrm{C} / \mathrm{W}$, and the results from quenching $\mathrm{T}_{\mathrm{Q}}=780^{\circ} \mathrm{C} / \mathrm{US59}$ are very close to those from quenching $\mathrm{T}_{\mathrm{Q}}=800{ }^{\circ} \mathrm{C} / \mathrm{W}[28]$.

The slightly higher carbon and manganese content of DP-B steel (compared to DP-A steel) determined (for both cooling mediums used) the obtaining of slightly higher values of the volume fraction of martensite in the structure and the ferrite microhardness, with effect on the ultimate tensile strength and total elongation (Tables 2-5).

Comparing the results obtained for the $\mathrm{DP}_{1.90 \mathrm{Mn}}$ steel (Table 6) with those determined for DP-A and DP-B steels (Tables 2-5), significant differences were observed between the data sets, differences determined, in particular, by the very different manganese content of the two categories of steels $[3,25,27,30]$.

Table 6. Volume fraction of martensite and mechanical properties for the $\mathrm{DP}_{1.90 \mathrm{Mn}}$ steel (average values).

\begin{tabular}{cccccc}
\hline $\mathrm{T}_{\mathbf{Q}}\left({ }^{\circ} \mathbf{C}\right)$ & $\mathbf{7 4 0}$ & $\mathbf{7 6 0}$ & $\mathbf{7 8 0}$ & $\mathbf{8 0 0}$ & $\mathbf{8 2 0}$ \\
\hline $\mathbf{V}_{\mathbf{M}} \mathbf{( \% )}$ & 25.10 & 42.51 & 57.10 & 68.32 & 78.10 \\
$\mathbf{R}_{\mathbf{m}} \mathbf{( M P a )}$ & 883 & 957 & 1018 & 1086 & 1135 \\
$\mathbf{A}_{\mathbf{5}} \mathbf{( \% )}$ & 16.68 & 15.18 & 14.04 & 12.99 & 12.06 \\
\hline
\end{tabular}

In $\mathrm{DP}_{1.9 \mathrm{Mn}}$ steel, the position of the critical points $\mathrm{A}_{\mathrm{c} 1}$ and $\mathrm{A}_{\mathrm{c} 3}$ led to the obtaining, by intercritical heating, of a higher amount of austenite, which determined the formation, on quenching, of a higher volume fraction of martensite. Thus, for the temperature range $760-820^{\circ} \mathrm{C}$, the volume fraction of martensite in the structure was higher by percentages between 22.32 and $41.12 \%$. Because of this, the values of ultimate tensile strength and total elongation at DP-A and DP-B steels were much different from those of DPS $1.90 \mathrm{Mn}$ steel (Figures 11 and 12); the total elongation was higher with percentages between 9.28 and 6.98 and the ultimate tensile strength was lower with values between 325.68 and $433.03 \mathrm{MPa}$. 


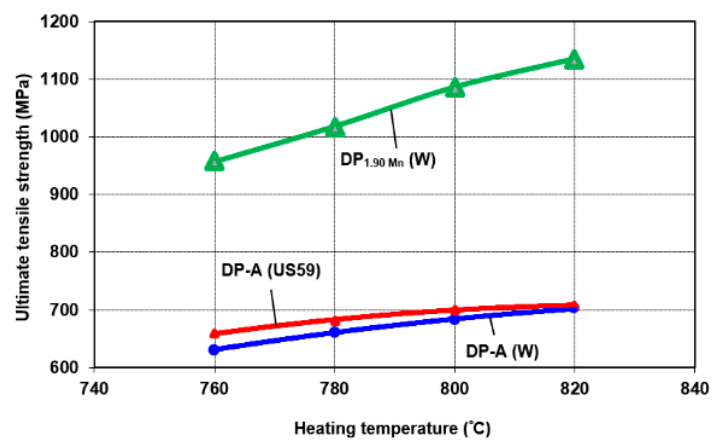

(a)

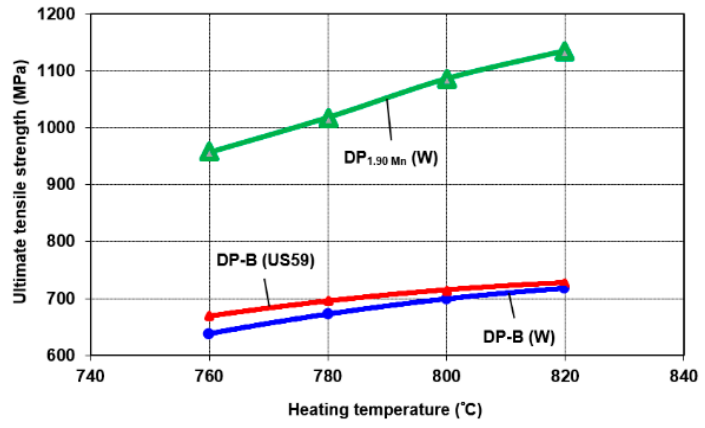

(b)

Figure 11. Variation of ultimate tensile strength with heating temperature and cooling medium: (a) DP 1.90Mn and DP-A steels; (b) DP 1.90Mn and DP-B steels.

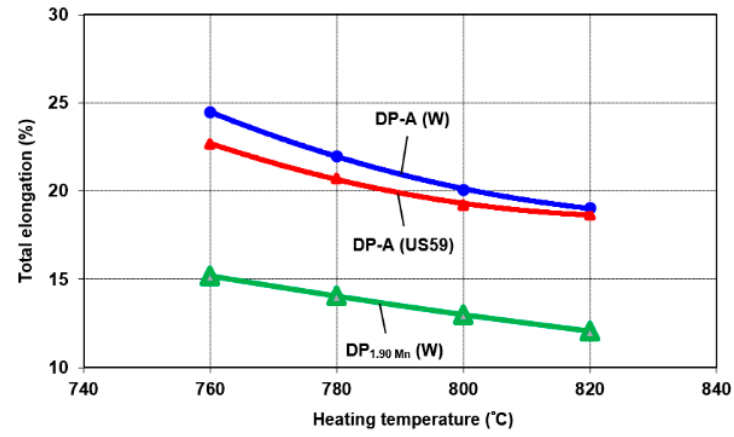

(a)

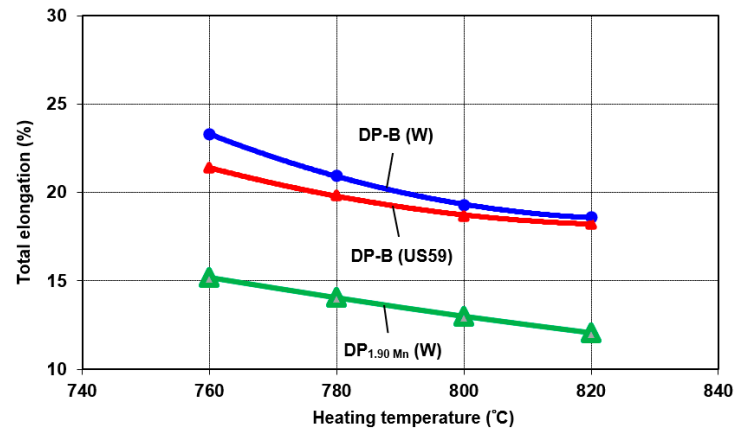

(b)

Figure 12. Variation of total elongation with heating temperature and cooling medium: (a) $\mathrm{DP}_{1.90 \mathrm{Mn}}$ and DP-A steels; (b) DP $1.90 \mathrm{Mn}$ and DP-B steels.

\section{Conclusions}

The increase, due to the rise in intercritical quenching temperature, of the volume fraction of martensite and ferrite microhardness in the structures has led to an increase of the ultimate tensile strength and the decrease of the total elongation of the dual-phase steels with low manganese content studied.

For the same heating temperatures, the use of the ultrasounds at cooling has led, also, to an increase in the volume fraction of martensite and ferrite microhardness in structures, resulting in a rise in the mechanical strength and a decrease in the deformability of the steels, because the ultrasounds at quenching eliminate the calefaction, enhance heat exchange between specimens and cooling medium, and provide an additional energy intake of the martensitic transformation.

The martensite obtained by quenching from temperatures close to the critical point $\mathrm{A}_{\mathrm{c} 1}$ (for both cooling mediums used) was in the form of small islands, situated mainly at the boundaries of the ferrite grains. At the same time, with the rising of the volume fraction of martensite in structures, an increase in the size of these islands is observed; furthermore, a tendency of their connection and the formation of a network around the ferrite grains are marked.

The additional energy intake from the quenching in water activated with ultrasounds, led to mechanical properties values, very close to those obtained by quenching in water without mechanical agitation, but conducted using a higher temperature heating.

The slightly higher carbon and manganese content of one of the studied steels has determined (for both cooling mediums used) the obtaining of slightly higher values of the volume fraction of martensite in the structure and the ferrite microhardness, with effect on the ultimate tensile strength and total elongation. 
The dual-phase steels with low manganese content (with $0.511 \mathrm{Mn}$, respectively $0.529 \% \mathrm{Mn})$ had mechanical characteristics $\left(\mathrm{R}_{\mathrm{m}}, \mathrm{A}_{5}\right)$ much different from those obtained for steel with $1.90 \%$ Mn ("classic" dual-phase steel).

Author Contributions: C.D., conceived and designed the experiments; C.D. and T.L.S., performed the experiments; C.D., analyzed the microstructures; T.L.S., D.A.C. and L.I., measured the mechanical properties; C.D., T.L.S., D.A.C. and L.I., discussed the data; C.D., wrote, revised, and edited the paper. All authors have read and agreed to the published version of the manuscript.

Funding: This research received no external funding.

Institutional Review Board Statement: Not applicable.

Informed Consent Statement: Not applicable.

Data Availability Statement: Not applicable.

Acknowledgments: The infrastructure used for this work was partially supported from the project "Integrated Center for research, development and innovation in Advanced Materials, Nanotechnologies, and Distributed Systems for fabrication and control (MANSiD)", Contract No. 671/2015, Sectoral Operational Program for Increase of the Economic Competitiveness co-funded from the European Regional Development Fund.

Conflicts of Interest: The authors declare no conflict of interest.

\section{References}

1. $\quad$ Rashid, M.S. Dual-Phase Steels. Ann. Rev. Mater. Sci. 1981, 11, 245-266. [CrossRef]

2. Golovanenko, S.A.; Fonshteyn, N.M. Dual-Phase Alloyed Steels; Metallurghia: Moscow, Russia, 1986; pp. 8-133.

3. Dulucheanu, C. Contributions Regarding the Physical, Mechanical and Technological Properties of the Ferrite-Martensite Dual-Phase Steels. Ph.D. Thesis, “Dunarea de Jos" University of Galati, Galati, Romania, 1999.

4. $\quad$ Davies, R.G.; Magee, C.L. Physical Metallurgy of Automotive High Strength Steels. In Structure and Properties of Dual-Phase Steels; Kot, R.A., Morris, J.W., Eds.; The Metallurgical Society of AIME: Warrendale, PA, USA, 1979; pp. 1-19.

5. Speich, G.R. Physical Metallurgy of Dual-Phase Steels. In Proceedings of the Fundamentals of Dual-Phase Steels, Chicago, IL, USA, 23-24 February 1981; Kot, R.A., Morris, J.W., Eds.; The Metallurgical Society of AIME: Warrendale, PA, USA, 1981; pp. 3-46.

6. Tsipouridis, P. Mechanical Properties of Dual-Phase Steels. Ph.D. Thesis, Technische Universität München, München, Germany, 2006.

7. Granbom, Y. Structure and Mechanical Properties of Dual-Phase Steels-An Experimental and Theoretical Analysis. Ph.D. Thesis, Royal Institute of Technology, Stockholm, Sweden, 2010.

8. Tasan, C.C.; Diehl, M.; Yan, D.; Bechtold, M.; Roters, F.; Schemmann, L.; Zheng, C.; Peranio, N.; Ponge, D.; Koyama, M.; et al. An Overview of Dual-Phase Steels: Advances in Microstructure-Oriented Processing and Micromechanically Guided Design. Annu. Rev. Mater. Res. 2015, 45, 391-431. [CrossRef]

9. Liu, S.; Kouadri-Henni, A.; Gavrus, A. DP600 dual phase steel thermo-elasto-plastic constitutive model considering strain rate and temperature influence on FEM residual stress analysis of laser welding. J. Manuf. Process. 2018, 35, 407-419. [CrossRef]

10. Nadlene, R.; Esah, H.; Norliana, S.; Mohd Irwan, M.A. Study on the Effect of Volume Fraction of Dual Phase Steel to Corrosion Behaviour and Hardness. World Acad. Sci. Eng. Technol. 2011, 5, 564-567.

11. Pouranvari, M. Tensile Strength and Ductility of Ferrite-Martensite Dual Phase Steels. Metall. Mater. Eng. 2010, 16, 187-194.

12. Birgani, E.N.; Pouranvari, M. Effect of Martensite Volume Fraction on the Work Hardening Behavior of Dual-Phase Steels. Available online: http:/ / konsys-t.tanger.cz/files/proceedings/metal_09/Lists/Papers/107.pdf (accessed on 6 April 2013).

13. Chatterjee, D. Behind the Development of Advanced High Strength Steel (AHSS) Including Stainless Steel for Automotive and Structural Applications-An Overview. Mater. Sci. Metall. Eng. 2017, 4, 1-15.

14. Keeler, S.; Kimchi, M.; Mooney, P.J. Advanced High-Strength Steels. Application Guidelines Version 6.0. Available online: http:/ / www.worldautosteel.org/download_files/AHSS\%20Guidelines\%20V6/00_AHSSGuidelines_V6_20170430.pdf (accessed on 10 December 2021).

15. Garcia, C.I.; DeArde, A.J. The formation of austenite in low-alloy steels. In Proceedings of the Structure and Properties of Dual-Phase Steels, New Orleans, LA, USA, 19-21 February 1979; Kot, R.A., Morris, J.W., Eds.; The Metallurgical Society of AIME: Warrendale, PA, USA, 1979; pp. 40-61.

16. Wycliffe, P.; Purdy, G.R.; Embury, J.D. Austenite growth in the intercritical annealing of ternary and quaternary dual-phase steels. In Proceedings of the Fundamentals of Dual-Phase Steels, Chicago, IL, USA, 23-24 February 1981; Kot, R.A., Morris, J.W., Eds.; The Metallurgical Society of AIME: Warrendale, PA, USA, 1981; pp. 59-84.

17. Kogan, L.I.; Matrokhina, E.F.; Entin, R.I. Influence of Austenization in the Intercritical Temperature Range on the Structure and Properties of Low-Carbon Steels. Phys. Met. Metall. 1981, 52, 93-101. 
18. Adamczyk, J.; Grajcar, A. Heat treatment and mechanical properties of low carbon steel with dual-phase microstructure. J. Achiev. Mater. Manuf. Eng. 2007, 22, 13-20.

19. Kim, N.J.; Thomas, G. Effects of the constituents on the mechanical behavior of low carbon steels. Scr. Metall. 1984, 18, 37-42. [CrossRef]

20. Jeong, C.W.; Kim, C.H. Ferrite growth on cooling after intercritical annealing of a dual-phase steel. Scr. Metall. 1985, 19, 37-42. [CrossRef]

21. Bag, A.; Ray, K.K.; Dwrakadasa, E.S. Influence of Martensite Content and Morphology on Tensile and Impact Properties of High-Martensite Dual-Phase Steels. Metall. Mater. Trans. A 1999, 30, 1193-1202. [CrossRef]

22. Calcagnotto, M.; Ponge, D.; Raabe, D. Microstructure Control during Fabrication of Ultrafine Grained Dual-phase Steel: Characterization and Effect of Intercritical Annealing Parameters. ISIJ Int. 2011, 52, 874-883. [CrossRef]

23. Amza, G. Ultrasounds. Active Applications; AGIR: Bucharest, Romania, 2006; pp. 573-603.

24. Băncescu, N.; Dulucheanu, C.; Severin, T.L. The Quenching in Ultrasonic Field of the Bearing Steels. Advantages and Perspectives. Part 1: The Influence of the Quenching Technology on Hardness and Structure of a RUL 1 Steel. Metal. Int. 2013, XVIII, 43-48.

25. Dulucheanu, C.; Bancescu, N.; Severin, T.L. The Influence of Quenching Medium on the Structure and Mechanical Properties of the Dual-Phase Steel with 0.09\% C, 1.90\% Mn. Metal. Int. 2011, XVI, 25-28.

26. Dulucheanu, C.; Severin, T. The Influence of Ultrasounds on the Structure of some Low Carbon and Manganese Dual-Phase Steels. In Proceedings of the 17th International Multisciplinary Scientific GeoConferince SGEM 2017, Vienna, Austria, 27-29 November 2017; STEF92 Technology Ltd.: Sofia, Bulgaria, 2017; Volume 17, pp. 85-92.

27. Dulucheanu, C.; Bancescu, N.; Severin, T. Technological Characteristics of a Dual-Phase Steel with $0.09 \%$ C and $1.90 \%$ Mn Obtained by Intercritical Quenching. Adv. Mater. Res. 2013, 814, 60-67. [CrossRef]

28. Dulucheanu, C.; Severin, T.; Potorac, A.; Irimescu, L. Influence of intercritical quenching on the structure and mechanical properties of a dual-phase steel with low manganese content. Mater. Today Proc. 2019, 19, 941-948. [CrossRef]

29. Dulucheanu, C.; Băncescu, N.; Severin, T. The Influence of Quenching Temperature on the Mechanical Properties of a Dual-Phase Steel with $0.094 \%$ C and 0.53\% Mn. Appl. Mech. Mater. 2015, 808, 28-33. [CrossRef]

30. Dulucheanu, C.; Severin, T.L.; Cerlinca, D.A.; Irimescu, L.; Javorova, J. Mechanical properties of some dual-phase steels with low manganese content. In Proceedings of the Short Papers of the Fourth International Scientific Conference Alternative Energy Sources, Materials and Technologies (ARSMT '21), Ruse, Bulgaria, 14-15 June 2021; Georgiev, A., Ed.; “Imeon" Sole-Owner: Sofia, Bulgaria, 2021; Volume 3, pp. 85-86.

31. Dulucheanu, C.; Severin, T.L.; Potorac, A.; Irimescu, L. Determination of the critical points in solid-state transformation of some hypoeutectoid steels. E3S Web Conf. 2019, 95, 04004. [CrossRef]

32. Burikova, K.; Rosenberg, G. Quantification of Microstructural Parameter Ferritic-Martensite Dual-Phase Steel by Image Analysis Available online: http:/ / metal2013.tanger.cz/files/proceedings/metal_09/Lists/Papers/032_e.pdf (accessed on 22 October 2013).

33. Speich, G.R.; Miller, R.L. Mechanical properties of ferrite-martensite steels. In Proceedings of the Structure and Properties of Dual-Phase Steels, New Orleans, LA, USA, 19-21 February 1979; Kot, R.A., Morris, J.W., Eds.; The Metallurgical Society of AIME: Warrendale, PA, USA, 1979; pp. 145-182.

34. Sudersanan, P.D.; Kori, N.; Aprameyan, S.; Kempaiah, U.N. The Effect of Carbon Content in Martensite on the Strength of Dual Phase Steel. Bonfring Int. J. Ind. Eng. Manag. Sci. 2012, 2, 1-4.

35. Hansen, S.S.; Pradhan, R.R. Structure/Property Relationships and Continuous Yielding Behavior in Dual-Phase Steels. In Proceedings of the Fundamentals of Dual-Phase Steels, Chicago, IL, USA, 23-24 February 1981; Kot, R.A., Morris, J.W., Eds.; The Metallurgical Society of AIME: Warrendale, PA, USA, 1981; pp. 113-144. 